\title{
Quality gap of educational services at Zahedan University of Medical Sciences, Iran
}

\author{
Ali Kebriaei ${ }^{1}$ and Fayzollah Akbari ${ }^{2}$ \\ ${ }^{1}$ Department of Public Health, Zahedan University of Medical Sciences and Health Services, Mashahir Square, \\ Zahedan; ${ }^{2}$ School of Health, Tehran University of Medical Sciences, Enghelab Street, Tehran, Iran. \\ e-mail: kebria_noosh@yahoo.com
}

\begin{abstract}
This study aims to compare quality gap of educational services at Zahedan University of Medical Sciences from students and faculties viewpoints. In a cross-sectional study, survey questionnaire was completed by two distinct groups of respondents- 230 faculty members and 384 students. Mass majority of the both groups declared there was negative gap in each of the five dimensions. Mean quality gaps from viewpoint of both groups were negative. The largest mean quality gap from students and faculty members viewpoint was in the responsiveness and tangibility dimensions respectively. The largest and smallest differences between students and faculties viewpoint were in the responsiveness and tangibility dimensions.
\end{abstract}

\section{Introduction}

Quality is one of the competitive priorities, which has migrated from the literature of manufacturing strategy to the service arena ${ }^{1}$. Accordingly, service quality has been receiving much prominence because of its obvious relationship to costs $^{2}$, financial performance $e^{3,4}$, customer satisfaction ${ }^{5-7}$ and customer retention ${ }^{8-10}$.

Because of increased importance from the service sector, researchers are defining quality from a customer's perspective. Successful service organizations are characterized by focus on the customers $^{11}$. Quality service is defined as that in which the consumer's perception of service performance meets or exceeds their expectation of what the service firm should do. The key to service quality, then, is to meet or exceed consumer expectations. One problem with this model is that there may often be discrepancies between the consumer's viewpoints and the provider's model of what constitutes quality service ${ }^{1}$. Any differences between consumer viewpoints and the organization's perception of consumer viewpoints on quality are important to identify and determine the level and quality of service provided ${ }^{12}$.

However, customers view on the quality of services differ from the views of providers, managers and policy makers ${ }^{13}$. Speciously, in many circumstances judgments on the quality of service are formulated by the management or providers. In this situation, the provider may be working hard to deliver some aspect of service to which the consumer is indifferent. Conversely, consumers may be basing their opinion of quality on some factors which the provider assumes are unimportant ${ }^{1}$.

Alternatively, if the gap between providers and consumers converge, the consequences could be the generation of more repeat visits, encouragement of new business through favorable consumer comments leading to increased profits and a positive image for the organization. This would facilitate the manager in the development of appropriate managerial quality systems, which should maximize consumer satisfaction ${ }^{12}$.

For higher education institutions, students views cannot be inferred from managers or providers' views and it is important to look at what their students want and not to collect data based upon what the institution perceives its students find important ${ }^{14}$.

Research into service quality as perceived by students and faculty members in a higher educational context is somewhat scant ${ }^{1,15}$ and as far as we are aware, none of them has addressed the specific context of medical higher education in Iran. Within this context, the goal of the study was to determine: a) the level of quality gap perceived by faculty and students and b) the differences, if any, between the viewpoints of two groups. 
Survey results can help to determine whether managers need to improve the management of student viewpoint or adjust service levels (or both). It will also help educational management in the process determining where to allocate scarce resources. Furthermore, a study such as this would, at a minimum, extend the literature on service quality in higher education.

\section{Materials and Methods}

This cross sectional study was carried out during the first month of 2005 within the Zahedan University of Medical Sciences. The University in question has 2,180 students and 230 faculty members.

Survey questionnaire was completed by two distinct groups of respondents- faculty members (providers) and students (consumers). 384 students had been approached. Simple random sampling of the students was undertaken. All of the faculty population, regarding the limited number of them, was examined by census method.

The survey instrument was designed around the validated SERVQUAL instrument. SERVQUAL, developed by Parasuraman et al. ${ }^{16,17}$, is an established framework for the measurement of general service quality. The SERVQUAL model consists of 22 items regarding service attributes, which are grouped along five dimensions. This framework has been extensively used and tested across a wide range of public and private sector services $^{15}$, and was therefore chosen as the framework for the research.

The model begins with the assumption that individuals are able to articulate both their expectations of the general characteristics and determinants of quality service and also their perceptions of actual and current service quality for a specific service provider. The model therefore not only provides an assessment of views of current service quality; it also provides a yardstick in terms of their expectations of what that service quality should be ${ }^{18}$.

The data collection instrument consisted of three sections. An expectations section consisting of 22 statements and a perceptions section consisting of a matching set of statements. In the third part of the questionnaire samples provided demographic data about themselves.

A five-point Likert scale ranging from very important to very unimportant was used to measure the students and faculties expectations and the same scale ranging from strongly agree to strongly disagree was used to measure expression of their perceived experience on each aspect of service. Service quality gap was measured by computing the difference between the rating respondents assign to expectations and perceptions statements $(\mathrm{QG}=\mathrm{P}-\mathrm{E})$. Accordingly, a negative quality gap score was gained if the students and faculties expectations passed their perceptions; a positive quality gap score was gained if the perceptions exceed exceptions. If perceptions and expectations were equal, there was no quality gap.

Statements (in both the expectations and perceptions sections) are grouped into five dimensions: a) tangibles; b) reliability; c) responsiveness; d) assurance; and e) empathy. Tangibles represent the physical facilities, equipment, and appearance of personnel. Reliability refers to the ability to perform the promised service dependably and accurately. Responsiveness is the willingness to help participants and provide prompt attention. Assurance indicates courteous and knowledgeable employees who convey trust and confidence. The empathy dimension includes caring and individual attention to users ${ }^{11}$.

The items of original SERVQUAL were modified in English for educational services, and then translated into Farsi. Three experts in the field reviewed the questionnaire to determine its consensual validity and the wording of statements was also simplified. Modification of the instrument for different service settings is supported by the developers of the instrument ${ }^{19}$.

Lastly a pilot test was conducted with 30 other students and on a number of faculty members and final adjustment made accordingly. Using Cronbach's alpha coefficient, internal consistency of different items of expectations and perceptions were 0.88 and 0.84 for student questionnaire, and 0.86 and 0.93 for faculty one; all above the 0.7 recommended by Nunnally ${ }^{20}$.

For data collection, five female public health undergraduate students delivered questionnaires to selected respondents. Students were given verbal and written instructions, and completed the questionnaires during the first few min of class, resulting in a 100 percent response rate of those queried. Only 140 academics responded to the survey representing a response rate of $61 \%$.

Analysis was carried out using SPSS for Windows (version1 3.0). The Mann-Whitney test was chosen to test differences in means of the two populations. Statistical significance was considered achieved with $p$ value of less than 0.05 . 


\section{Results}

The results shows the mean age of the students was $21.98 \pm 3.21$ years. 67.1 percent of them were females and the rest were males. Of the students being studied, 35\% were in their first or second year of education, $37.2 \%$ spent 3-4 years and the rest had passed 4 years or more. $88 \%$ of the students were single and $12 \%$ were married.

The mean age of the faculty members was $39.2 \pm 6.7$ years and ranged from 27 to 56 years. 70 percent of them were males and the rest were females. The mean tenure with the organization was $7.5 \pm 4.9$ years.

Table I shows that the mean quality gaps from point of view of both groups in all the dimensions were negative. From students' viewpoint the largest mean quality gap was in the responsiveness, followed by empathy, assurance, tangibility and reliability dimensions. Faculty members stated that the largest mean quality gap was in the tangibility, followed by assurance, responsiveness, empathy and reliability dimensions. Smallest mean quality gap, from both groups' viewpoint was found in the reliability dimensions. The largest and smallest differences between students' and faculties' viewpoint were in the responsiveness and tangibility dimensions. A Mann-Whitney $U$ test revealed that significant differences in four of the dimensions were found between students and faculties.

Table I: Students' and faculties' viewpoint about quality gaps in the educational services

\begin{tabular}{|c|c|c|c|c|}
\hline \multirow[t]{2}{*}{ Dimensions } & \multicolumn{2}{|c|}{ Quality gap (M $\pm \mathrm{SD})$} & \multirow[t]{2}{*}{ Difference } & \multirow{2}{*}{$\begin{array}{c}\text { Mann- } \\
\text { Whitney } \\
\text { U test }\end{array}$} \\
\hline & Student & Faculty & & \\
\hline Responsiveness & $-1.73 \pm 1.11$ & $-0.78 \pm 0.78$ & 0.95 & $<0.0001$ \\
\hline Empathy & $-1.55 \pm 1.10$ & $-0.68 \pm 0.71$ & 0.87 & $<0.0001$ \\
\hline Reliability & $-1.11 \pm 1.00$ & $-0.31 \pm 0.57$ & 0.80 & $<0.0001$ \\
\hline Assurance & $-1.53 \pm 1.10$ & $-0.91 \pm 0.60$ & 0.62 & $<0.0001$ \\
\hline Tangibility & $-1.32 \pm 1.22$ & $-1.14 \pm 0.83$ & 0.18 & ns \\
\hline
\end{tabular}

Table II reveals that the mass majority of both students and faculties declared there was negative quality gap in each of the five dimensions of educational services. The mass majority of both students and faculties declared there was negative quality gap in each of the five dimensions of educational services. In general, as compared with students, smaller percent of faculties stated there was no quality gap in each of the five dimensions of educational services. Also, higher percent of them stated there was positive quality gap in each of the five dimensions of educational services.

Table II. Frequency and percentage of students and faculties making comments about quality gap in the educational services

\begin{tabular}{lcccccc}
\hline Dimensions & \multicolumn{2}{c}{$\begin{array}{c}\text { Negative quality } \\
\text { gap n (\%) }\end{array}$} & \multicolumn{2}{c}{$\begin{array}{c}\text { No quality gap } \\
\text { n (\%) }\end{array}$} & \multicolumn{2}{c}{$\begin{array}{c}\text { Positive quality } \\
\text { gap n (\%) }\end{array}$} \\
\cline { 2 - 7 } & Student & Faculty & Student & Faculty & Student & Faculty \\
\hline Respon- & 334 & 108 & 42 & 10 & 8 & 22 \\
siveness & $(87)$ & $(77.1)$ & $(10.9)$ & $(7.1)$ & $(2.1)$ & $(15.7)$ \\
& 318 & 118 & 53 & 6 & 13 & 16 \\
Empathy & $(82.8)$ & $(84.3)$ & $(13.8)$ & $(4.3)$ & $(3.4)$ & $(11.4)$ \\
& 315 & 128 & 62 & 4 & 7 & 8 \\
Assurance & $(82)$ & $(91.4)$ & $(16.2)$ & $(2.9)$ & $(1.8)$ & $(5.7)$ \\
& 280 & 100 & 87 & 10 & 17 & 30 \\
Reliability & $(72.9)$ & $(71.4)$ & $(22.7)$ & $(7.1)$ & $(4.4)$ & $(21.4)$ \\
& 275 & 124 & 92 & 10 & 17 & 6 \\
Tangibility & $(71.6)$ & $(88.6)$ & $(24)$ & $(7.1)$ & $(4.4)$ & $(4.3)$ \\
\hline
\end{tabular}

The five largest differences between viewpoints of two groups regarding quality gap on statements was observed in: two statements relating to empathy, two statements relating to responsiveness and one statement in the tangibility dimension (Table III). Analyzing these five highest statements indicated that differences between viewpoints of two groups were significant.

The five lowest differences between viewpoints of two groups regarding quality gap on statements was observed in: three statements in the tangibility, one statement in the reliability and one statement in the responsiveness dimension (Table IV). Analyzing these five lowest statements indicated that differences between viewpoints of two groups were only in two statements significant.

\section{Discussion}

This study shows that mean quality gaps from viewpoints of both groups in all the dimensions were negative (Table I). The results indicate that service quality in all dimensions was generally below expectations of both groups. On the other hand, it suggests that educational management did

Table III. The five statements with highest differences

\begin{tabular}{|c|c|c|c|c|}
\hline \multirow[t]{2}{*}{ Statements } & \multicolumn{2}{|c|}{ Quality gap (M $\pm \mathrm{SD})$} & \multirow[t]{2}{*}{ Difference } & \multirow{2}{*}{$\begin{array}{l}\text { Mann- } \\
\text { Whitney U test }\end{array}$} \\
\hline & Student & Faculty & & \\
\hline School office staff/faculty take care to understand my request & $-1.82 \pm 1.44$ & $0.09 \pm 0.94$ & 1.91 & $<0.0001$ \\
\hline $\begin{array}{l}\text { School office staff/faculty tell me exactly when they are able to attend to my } \\
\text { request }\end{array}$ & $-1.76 \pm 1.45$ & $-0.53 \pm 1.18$ & 1.23 & $<0.0001$ \\
\hline School office staff/faculty give me prompt service & $-1.98 \pm 1.50$ & $-0.76 \pm 1.10$ & 1.22 & $<0.0001$ \\
\hline The behavior of school office staff/faculty instills confidence in me & $-1.60 \pm 1.41$ & $-0.40 \pm 0.93$ & 1.20 & $<0.0001$ \\
\hline School office staff/faculty deal with me in a caring and courteous manner & $-1.06 \pm 1.54$ & $0.06 \pm 1.24$ & 1.12 & $<0.0001$ \\
\hline
\end{tabular}


Table IV: The five statements with lowest differences

\begin{tabular}{|c|c|c|c|c|}
\hline \multirow[t]{2}{*}{ Statements } & \multicolumn{2}{|c|}{ Quality gap (M $\pm \mathrm{SD})$} & \multirow[t]{2}{*}{ Difference } & \multirow{2}{*}{$\begin{array}{c}\text { Mann-Whitney U } \\
\text { test }\end{array}$} \\
\hline & Student & Faculty & & \\
\hline The school office is equipped with modern technology & $-0.86 \pm 1.55$ & $0.67 \pm 1.07$ & 0.19 & ns \\
\hline School office staff/faculty keep error-free records & $-0.67 \pm 1.38$ & $-0.47 \pm 1.11$ & 0.20 & ns \\
\hline The school office staff/faculty dress smartly & $-0.66 \pm 1.59$ & $-0.90 \pm 0.98$ & 0.24 & 0.02 \\
\hline The school office has a professional appearance & $-2.08 \pm 1.55$ & $-1.81 \pm 1.40$ & 0.27 & ns \\
\hline School office staff/faculty are always willing to help me & $-1.13 \pm 1.23$ & $-0.81 \pm 0.84$ & 0.32 & 0.01 \\
\hline
\end{tabular}

not manage the factors influencing expectations or perceptions of both groups: hence the quality gap recognized. These results imply that there is room for improvement, particularly in the eyes of students, and educational service quality in all the five dimensions could be improved.

Students' viewpoints showed that the largest mean quality gap was in the responsiveness dimension.

This finding is similar to some studies ${ }^{17,21,22}$ whereas is not consistent with some other studies $^{15,23-25}$. Students' views clearly show that responsiveness, empathy and assurance are the three most critical dimensions of educational services. They wanted knowledgeable and enthusiastic individuals who cared about their learning and helped them as individuals to move their knowledge forward. Students expect academic staff to understand their needs, deal with them in a caring fashion, and have knowledge of course provision. As it is a prerequisite to having knowledgeable and service-oriented employees to serve costumers better ${ }^{26}$, the management should allocate resources to the training of their staff and faculty, so that they will feel confident and able to provide prompts/personalized and caring service to students to decrease the gap in these dimensions and satisfy their students.

Because students considered empathy and responsiveness as critical dimensions, the management needs to recognize the importance of the behavioral aspects of service that were enclosed mainly by these dimensions. The employee's ability and willingness to satisfy, and his/her manner and appearance, all play a part in determining how satisfied the customer is with the service encounter $^{14}$. The implication for management is to ensure, as part of a total quality management program, the appropriate selection and training of service staff to be able to perform not only the physical tasks but be able to display the qualities of responsiveness and empathy. These critical dimensions, as the key areas for improvement, are not particularly resource intensive problem to fix (when compared to, for example, staff competence or physical working environment). In this regard oldfield believed that showing courtesy and a sincere interest towards students does not cost anything, but can reap great benefits. In many ways, employees may be the only way a service provider can differentiate itself; for example, in terms of politeness, knowledge and helpfulness compared to employees delivering competitive services ${ }^{14}$.

While these results are disquieting, the faculty results are better. They believe that they are failing to meet expectations to a much smaller degree since their mean scores are less negative than those of the students. It is believed that some expectations are not achievable within the constraints of budget, regulations or other factors ${ }^{11}$. As compared with students, faculties have additional and important knowledge in relation to the provision of the service and are somewhat aware of such difficulties. This could result in a lower quality gaps views.

This study found that from faculties' viewpoints the largest mean quality gap was in the tangible dimension. This was in keeping with findings of Pariseau \& McDaniel $^{1}$, and Galloway ${ }^{15}$. Considering that part of the tangibility dimension is the physical working environment for faculty, it is understandable that their expectations might be higher than those of the students and confirm largest mean quality gap in this dimension. However, educational management needs to place emphasis on tangibles but not to the extent of consuming excessive finance which may be better used to meet the students' other expectations such as responsiveness and empathy. Although both faculty and students established smallest mean quality gap in reliability dimension, they differed in the rank ordering of the remaining dimensions. The largest mean quality gap for students was in responsiveness, which is ranked third by faculties. The second largest mean quality gap for students was in empathy, which is ranked fourth by faculty. In the same manner, the faculties have rank tangibles first while students have ranked it fourth, though mean quality gap for faculty $(-1.14)$ was smaller than those of students $(-1.32)$ in this dimension. Generally, mean quality gaps for faculty in all the five dimensions were lower than whatever confirmed by students. It seems usual that providers (faculty) also recognize somewhat negative mean quality gap because they also believe that organization could provide better services to customers. 
Although differences between students' and faculties' viewpoints regarding quality gap in four dimensions were significant, the good news is that it was not significant for tangibility dimension. If students and faculty agree that service quality exceeds, meets or falls below expectations, then there is common ground for continuation or improvement of the level of service quality. But if providers are unaware of a failure to meet expectations, the prognosis for improvement is poor ${ }^{1}$.

To conclude, in the resource-constrained climate of the medical higher education in Iran, where students' expectations are continually increasing, and where there is a recognized need for managers to update their service improvement decisions. On the basis of students priorities, this research study suggests that there is considerable scope for applying gap analysis methodology in medical higher education contexts.

\section{Acknowledgements}

The authors are grateful for the Zahedan University of Medical Sciences authorities for their support both financially and administratively. We are grateful to Mrs. Maryam Kebriaei for reviewing the manuscript. Also thanks to the respondents who participated in the study.

\section{References}

1. Pariseau SE, McDaniel JR. Assessing service quality in Schools of Business. Int J Qual Reliab Manag. 1997; 14: 204-18.

2. Kellogg, DL, Youngdahl WE, Bowen DE. On the relationship between customer participation and satisfaction: Two frameworks. Int J Ser Ind Manag. 1997; 8: 206-19.

3. Hallowell R. The relationships of customer satisfaction, customer loyalty and profitability: An empirical study. Int J Ser Ind Manag. 1996; 7: 27-42.

4. Rust RT, Keiningham TL, Clemens S, Zahorik AJ. Return on quality at chase Manhattan Bank. Interfaces 1999: 62-72.

5. Stauss B, Neuhaus P. The qualitative satisfaction model. Int J Ser Ind Manag. 1997; 8: 236-49.

6. Shemwell DJ, Yavas U, Bilgin Z. Customer-service provider relationships: An empirical test of a model of service quality, satisfaction and relationship oriented outcome. Int J Ser Ind Manag. 1998; 9: 155-68.

7. Soderlund M. Customer satisfaction and its consequences on customer behavior revisited: The impact of different levels of satisfaction on word-ofmouth, feedback to the supplier and loyalty. Int J Ser Ind Manag. 1998; 9: 169-88.

8. Keaveney SM. Customer switching behavior in service industries: An exploratory study. J Marketing 1995; 59: 71-82.

9. Boshoff C. An experimental study of service recovery options. Int J Ser Ind Manag. 1997; 8: 110-30.
10. Hocutt MA. Relationship dissolution model: Antecedents of relationship commitment and the likelihood of dissolving a relationship. Int J Ser Ind Manag. 1998; 9: 189-200.

11. Juwaheer TD. Exploring international tourists' perceptions of hotel operations by using a modified SERVQUAL approach: A case study of Mauritius. Manag Ser Qual. 2004; 14: 350-64.

12. Douglas L, Connor R. Attitudes to service quality: The expectation gap. Nutr Food Sci. 2003; 33: 165-72.

13. Campen CV, Sixma HJ, Kerssens JJ, Peters L, Rasker JJ. Assessing patients' priorities and perceptions of the quality of health care: The development of the quoterheumatic-patients instrument. Bri J Rheumatol. 1998; 37: 362-68.

14. Oldfield BM, Baron S. Student perceptions of service quality in a UK university business and management faculty. Qual Assurance Edu. 2000; 8: 85-95.

15. Galloway L. Quality perceptions of internal and external customers: A case study in educational administration. TQM Magazine 1998; 10: 20-26.

16. Parasuraman A, Zeithaml VA, Berry LL. A conceptual model of service quality and its implications for future research. J Marketing 1985; 49: 41-50.

17. Parasuraman A, Zeithaml VA, Berry LL. SERVQUAL: A multiple item scale for measuring consumer perceptions of service quality. J Retailing 1988; 64: 1240.

18. Donnelly M, Wisniewski M, Dalrymple JF, Curry AC. Measuring service quality in local government: The SERVQUAL approach. Int J Public Sector Manag. 1995; 8: 15-20.

19. Parasuraman A, Zeithaml VA, Berry LL. Alternative scales for measuring service quality: A comparative assessment based on psychometric and diagnostic criteria. J Retailing 1994; 70: 201-30.

20. Nunnally JC. Psychometric theory. Englewood-Cliffs, NJ, McGraw-Hill Book Company, 1988.

21. Karydis A, Komboli M, Panis V. Expectations and perceptions of Greek patients regarding the quality of dental health care. Int J Qual Health Care 2001; 13: 409-16.

22. Lim PC, Tang NKH. A study of patients' expectations and satisfaction in Singapore Hospitals. Int J Health Care Qual Assurance 2000; 13: 290-99.

23. Tyran CK, Ross SC. Service quality expectations and perceptions: Use of the SERVQUAL instrument for requirements analysis. Issues Information Systems 2006; 7: 357-62.

24. Westbrook TS, Greiner K, Saunders K. Student perceptions of academic service and instructional quality over a four-year academic experience. J Res Edu. 2005; 15: 70-83.

25. Wisniewski M, Wisniewski $H$. Measuring service quality in a hospital colposcopy clinic. Int J Health Care Qual Assurance 2005; 18: 217-28.

26. Ugboma C, Callistus I, Ogwude IC. Service quality measurements in ports of a developing economy: Nigerian ports survey. Manag Ser Qual. 2004; 14: 487-95. 